\title{
¿Dejarías que un dentista te operara del corazón? Sobre las Administraciones que quieren ser electrónicas...
}

\author{
Por Pilar Sánchez-Vicente
}

\begin{abstract}
Resumen: En los años recientes, las administraciones públicas han gastado grandes sumas de dinero para informatizarse, pero desgraciadamente han olvidado consultar a quienes más saben de gestión de información, un error que a veces han pagado caro.

Palabras clave: Administración pública, TICs, Tecnologías de la información y la comunicación, Profesionales de la información, Consultoría.

Title: Would you allow that a dentist would operate on your heart? About Administrations who want to be electronic...

Abstract: In recent years, governments have spent large amounts of money to computerize the public administration, but unfortunately they have forgotten to consult those most aware of information management, a mistake that sometimes have paid dearly.
\end{abstract}

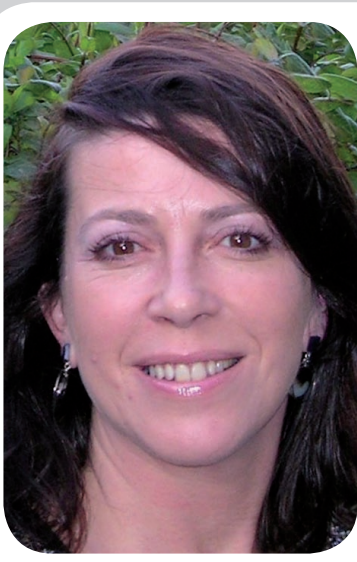

Pilar Sánchez-Vicente, documentalista y escritora, es licenciada en geografía e historia por la Univ. de Oviedo. Es jefa del Servicio de Publicaciones, Archivos Administrativos y Documentación del Gobierno del Principado de Asturias. Responsable de los contenidos del portal www. asturias.es y del Boletín Oficial del Principado de Asturias. Recibió el premio Adolfo Posada 2005 por el Sidra (Sistema de Información Documental en Red de Asturias).

Keywords: Public administration, ICT, Information and communication technologies, information professionals, Consulting.

Pilar Sánchez-Vicente. ¿Dejarías que un dentista te operara del corazón? Sobre las Administraciones que quieren ser electrónicas... En: El profesional de la información, 2008, v. 17, n. 2, marzo-abril, pp. 221-223.

DOI: 10.1345/epi.2008.mar.13

CONOZCO A LA ADMINISTRACIÓN desde hace mucho tiempo, veintiún años concretamente, de los cuales he pasado más horas con ella que con mi familia, amigos, aficiones..., sé que contribuye a que tengamos sanidad, educación, justicia..., un lugar en el que trabajaron, trabajamos, cientos de miles de personas al servicio de la ciudadanía, cada una en su ámbito. Hoy quiero hablar de mi área, la Información.

Aún recuerdo cuando entró la máquina eléctrica en el centro, en un despacho a rebosar de libros y papeles, y, poco después, el primer ordenador. A partir de ahí, el proceso fue imparable y lo sigue siendo a pasos agigantados: la explosión de información. En nuestro sector conocíamos la sustancia, somos expertos en la materia. Estábamos acostumbrados a modelarla, a conservarla, a protegerla y fuimos conscientes de que ipor fin! se había hecho la luz. Habituados a las cavernas, los viajes intelestares se abrieron ante nuestros ojos. Y, embarcados en la Infoesfera, aprendimos a volar.

Los patrones de búsqueda se rompieron con internet y hoy izamos la bandera global del acceso abierto, universal y gratuito a la información. La Red facilita el trabajo en red y eso creó nuevas formas de relación, equipos en distancia multidisciplinares, intercambio del conocimiento, innovación, renovación... Los profesionales que trabajábamos en este campo asumimos el desafío y empezamos a introducir conceptos como arquitectura de la información, usabilidad, gestión automatizada, accesibilidad... Las fronteras entre archiveros, bibliotecarios y documentalistas se diluyeron, para dar paso a la figura del siglo XXI: el profesional de la información.

\section{"La información pasó de ser un cajón cerrado a convertirse en el motor vital de la economía"}

La Administración intentó adaptarse a las novedades, a las demandas de los usuarios, a las nuevas tecnologías, a la Sociedad de la Información. La expansión del mercado produjo un verdadero vuelco. Y la información, el corazón de su gigantesco cuerpo, pasó de ser un cajón cerrado a convertirse en el motor vital de la economía y rendimiento. Daba igual que se tratara de agricultura, ganadería, infraestructuras; que los destinatarios fueran jóvenes, mayores, inmigrantes. En cualquier sector se hizo necesario automatizar los procedimientos, las tradicionales gestiones manuales. La informa- 
ción, independientemente de la fuente o el soporte, debía ser tratada, procesada, difundida... casi a la carta. Más tarde que temprano, se hicieron portales para ofrecer servicios y trámites por internet, atender a los ciudadanos de forma multicanal, etc.

Y, entonces, se reclutó a un ejército de informáticos, internos, externos, mediopensionistas, creyendo que así se conseguirían los objetivos. Que por juntar ladrillos en el solar se tendría una casa, y que por comprar pintura iba a pintarse sola. Casi nadie se preocupó de racionalizar, de simplificar, de analizar, de optimizar lo existente, de procurar el retorno de la inversión. De orientar la galería al sur, hacer escaleras anchas y rampas opcionales, habitaciones de amplias ventanas, paredes luminosas, pasillos a un clic. Alegremente, se prescindió del factor humano, llamando a las máquinas "servidores" y se dió por servida.

No se comprendió que es imposible programar el conocimiento, que entre el mundo real y el virtual, media un abismo. No es lo mismo "firme y selle" que "firma digital y sellado de tiempos", ni papel que pantalla, ni un DIN A4 que una página web. Entre las "funciones" que realiza un gestor y las "aplicaciones" que las pretendían suplir, faltaba un eslabón, el más importante de la cadena: aquel que era capaz de traducir el lenguaje natural al informático, de aplicar el sentido común, de adaptarse a las nuevas exigencias. Quienes conocían a las personas de cerca, a pie de obra, y sabían de sus miserias y ambiciones, su rechazo y su necesidad, sus hábitos y sus motivaciones; pero también conocían la Administración, sus recovecos, su legitimidad y arbitrariedad, sus fortalezas y debilidades, su inmenso potencial y la leyenda negra que le acompaña. Pero, sobre todo, eran especialistas en controlar los factores que se empezaban a desbordar.

La Administración, en lugar de apreciarnos en nuestra justa valía, de pedirnos consejo y tenernos presentes en todos los proyectos, exigiendo también a las empresas privadas esa cualificación en sus equipos, prescindió de nuestra ayuda a la hora del mayor reto que nunca haya tenido que afrontar. Compitió contra un mundo que cambiaba y le rebasa en cada instante. Corre detrás, pero no lo alcanza. Obcecada, compra motos que no tienen ruedas, barcos sin orza, aviones sin alas. Busca el oro en su reflejo, sin reconocer que lo guardan sus entrañas.

\section{"La Administración prescindió de los profesionales de la información a la hora del mayor reto que nunca haya tenido que afrontar"}

¿De qué sirvieron los sistemas náufragos, los idos al limbo desaparecido, los costosos productos que nunca se utilizan? No se trata de diseñar sistemas que enmascaran tras un cool look\&feel la árida realidad cotidiana de la desesperación de los usuarios, bien por la lentitud, bien por la complejidad, bien por la incapacidad de las herramientas. La Administración Pública es parte y todo de los habitantes de un país, pues se nutre de sus impuestos, nos alimenta. Es su derecho y nuestro deber devolverles con creces lo que pagan. Nosotros podemos ayudar, es nuestro oficio, insisto.

Cómo hacer sencillo lo complejo, fácil lo difícil, rápido lo lento; entendible el lenguaje críptico, asequibles los complejos trámites. Eso es de lo que nosotros sabemos. Somos especialistas en hacer latir su viejo corazón, en mantener su cuerpo con vida a lo largo de estos miles de años. Somos las hormigas frente al caos, las que intentan normalizar, describir, organizar, agilizar, conservar, facilitar el acceso a todo lo que lo que la Administración da y quita, con seguridad y ajuste a la ley.

Y la Administración, que se precia de tener el más selectivo acceso de su personal, que establece las normas y vigila que se cumplan, que convoca restrictivas pruebas para garantizar la limpia obtención de los mejores candidatos..., prescinde de los profesionales que le permitirían convertir en éxito los fracasos que acumula. No le reprocho nada, ¡todo es tan nuevo para la Administración!

Cierto es que todos trabajamos con información, sí, los ladrillos, el cemento, el andamio, la grúa...,

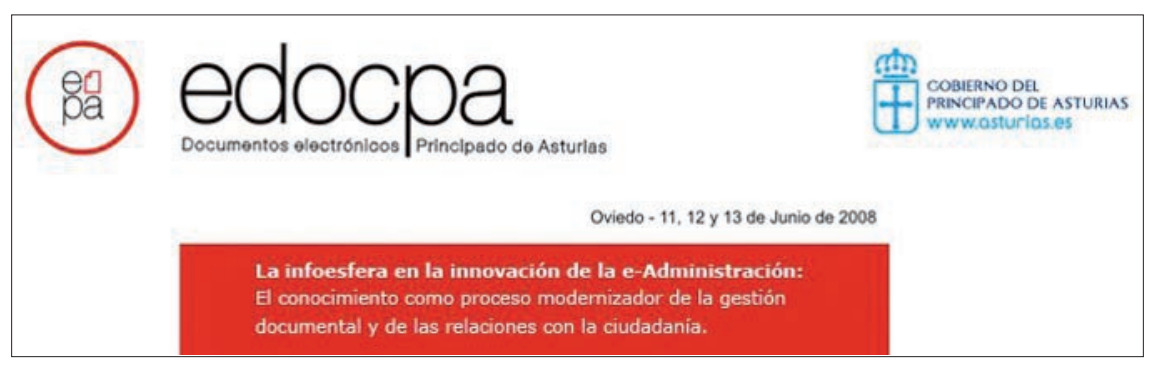

PD: Si quieres conocer mejor cómo las tecnologías de la información y de la comunicación pueden integrarse en la Administración, y saber por dónde van los tiros, acude al II Coloquio Internacional sobre documentos electrónicos, E-DOCPA 2008, auspiciado por el Gobierno del Principado de Asturias, que tendrá lugar del 11 al 13 de junio en Oviedo, bajo el lema "La infoesfera en la innovación de la e-Administración: la innovación como proceso modernizador de la gestión documental y de las relaciones con la ciudadanía". http://www.edocpa.com 
son elementos comunes. Pero sólo el ingeniero tiene la formación suficiente y necesaria para construir un puente o diseñar una autopista. Quien esto escribe sabe bien qué hace, e insiste: todos son médicos, sí, todos titulados, todos expertos, todos operan sobre nuestros cuerpos, pero, ¿alguien consentiría que un dentista interviniera en nuestro corazón? Seguro que nos pondríamos en manos de un especialista...

Con cariño, respeto y renovada ilusión por hacer la Administración
Pública cada día mejor. Pese a su ingrata resistencia.

Pilar Sánchez Vicente

Coordinadora General del E-DOCPA.

pilarsv@princast.es

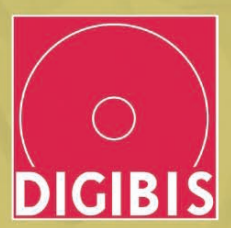

\section{Definimos espacios virtuales avanzados para la gestión del conocimiento en la Web y la preservación digitol a largo plazo}

\section{Herramientas para crear espacios virtuales}

DICIAROH 1.6

Sistema digital de descripción y gestión archivística

DICIBIB 4.0

Solución avanzada para la creación de Bibliotecas Digitales y la Gestión Bibliotecaria Multilingüe

Digifolizeción avernzada Con asignación dinámica de metadatos

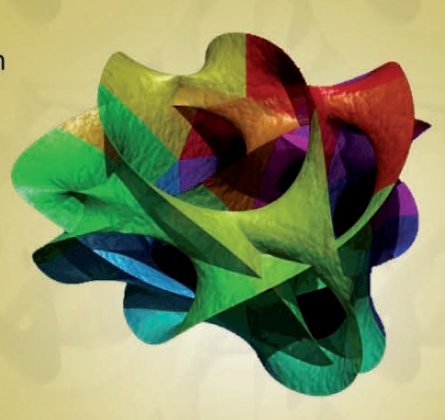

OAsls-PMH 2.0

Sistema integrado de recolección de diversos esquemas de metadatos.

DCMI sin cualificar MARC 21

EAD

mod_OAl

ePrints (diversos esquemas)

Ponderación de repositorios

\section{ORACLE PARTNERNETWORK}
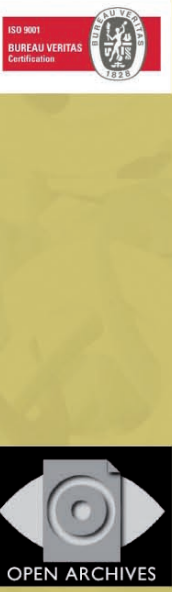

Validación en el Data Providers de la Open Archives Intiative.

SiteMaps con Google y Yahoo. metadatos en METS (diferentes Profiles) en repositorios OAl v2.0

- Tecnologías abiertas para la creación, recuperación (MARCXML, DCMI y RDF)

- Repositorios Institucionales para Preservación Digital a largo plazo mediante PREMIS y OAIS ISO 14721

Recolección en la Web para Entidades e Instituciones de Memoria en OAI-PMH y Dublin Core e intercambio de

- Consultoría y mappings a DCMI para implementación y recolección de metadatos y anotación de instancias

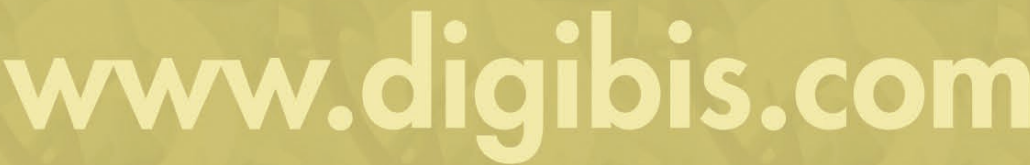


